\title{
Relation to Reference Period
}

National Cancer Institute

\section{Source}

National Cancer Institute. Relation to Reference Period. NCI Thesaurus. Code C49638.

An abstraction belonging to or characteristic of a point or period to something that refers or points to an interval of time characterized by the occurrence of a certain condition, event, or phenomenon. 